\title{
Deactivation of silicon surface states by Al-induced acceptor states from Al-O monolayers in $\mathrm{SiO}_{2}$
}

Cite as: J. Appl. Phys. 125, 015301 (2019); https://doi.org/10.1063/1.5054703

Submitted: 02 September 2018 . Accepted: 13 December 2018. Published Online: 04 January 2019

Daniel Hiller (D), Paul M. Jordan, Kaining Ding, Manuel Pomaska (D), Thomas Mikolajick (D), and Dirk König (i)
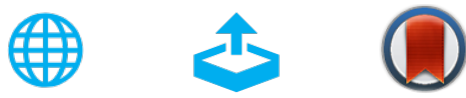

View Online

Export Citation

\section{ARTICLES YOU MAY BE INTERESTED IN}

Perspective: Nanoscopy of charge kinetics via terahertz fluctuation

Journal of Applied Physics 125, 010901 (2019); https://doi.org/10.1063/1.5079534

Phonon properties and thermal conductivity from first principles, lattice dynamics, and the Boltzmann transport equation

Journal of Applied Physics 125, 011101 (2019); https://doi.org/10.1063/1.5064602

Realization of rhombohedral, mixed, and tetragonal like phases of $\mathrm{BiFeO}_{3}$ and ferroelectric domain engineering using a strain tuning layer on $\mathrm{LaAlO}_{3}(001)$ substrate Journal of Applied Physics 125, 012501 (2019); https://doi.org/10.1063/1.5054372

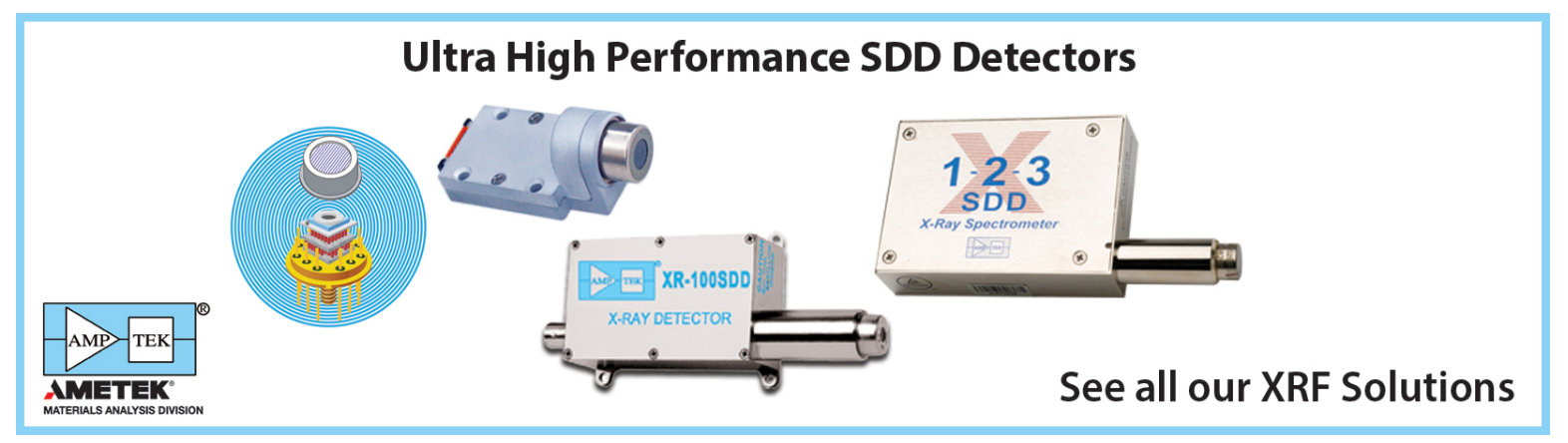




\title{
Deactivation of silicon surface states by Al-induced acceptor states from Al-O monolayers in $\mathrm{SiO}_{2}$
}

\author{
Cite as: J. Appl. Phys. 125, 015301 (2019); doi: 10.1063/1.5054703 \\ Submitted: 2 September 2018 . Accepted: 13 December 2018 . \\ Published Online: 4 January 2019
}

\author{
Daniel Hiller, ${ }^{1, a)}$ (D) Paul M. Jordan, ${ }^{2, b)}$ Kaining Ding, ${ }^{3}$ Manuel Pomaska, ${ }^{3}$ (D) Thomas Mikolajick, ${ }^{2,4}$ (D) \\ and Dirk König ${ }^{5, a)}$ (D)
}

\begin{abstract}
AFFILIATIONS
${ }^{1}$ Research School of Engineering, Australian National University, Canberra, Australian Capital Territory 2601, Australia

${ }^{2}$ Nanoelectronic Materials Laboratory g GmbH (NaMLab), 01187 Dresden, Germany

${ }^{3}$ IEK5-Photovoltaik, Forschungszentrum Jülich, 52425 Jülich, Germany

${ }^{4}$ Institut für Halbleiter- und Mikrosystemtechnik, TU Dresden, 01062 Dresden, Germany

${ }^{5}$ Integrated Materials Design Centre, University of New South Wales, Sydney, New South Wales 2052, Australia
\end{abstract}

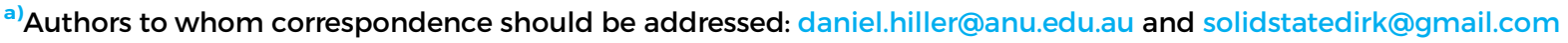

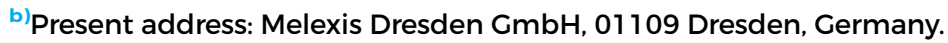

\begin{abstract}
$\mathrm{Al}-\mathrm{O}$ monolayers embedded in ultrathin $\mathrm{SiO}_{2}$ were shown previously to contain $\mathrm{Al}$-induced acceptor states, which capture electrons from adjacent silicon wafers and generate a negative fixed charge that enables efficient Si-surface passivation. Here, we show that this surface passivation is just in part attributed to field-effect passivation, since the electrically active interface trap density $\mathrm{D}_{\mathrm{it}}$ itself at the $\mathrm{Si} / \mathrm{SiO}_{2}$ interface is reduced by the presence of the acceptor states. For sufficiently thin tunnel- $\mathrm{SiO}_{2}$ films between the Si-surface and the Al-O monolayers, $\mathrm{D}_{\mathrm{it}}$ is reduced by more than one order of magnitude. This is attributed to an interface defect deactivation mechanism that involves the discharge of the singly-occupied dangling bonds $\left(\mathrm{P}_{\mathrm{bo}}\right.$ defects) into the acceptor states, so that Shockley-Read-Hall-recombination is drastically reduced. We demonstrate that the combined electronic and field-effect passivation allows for minority carrier lifetimes in excess of $1 \mathrm{~ms}$ on n-type $\mathrm{Si}$ and that additional $\mathrm{H}_{2}$-passivation is not able to improve that lifetime significantly.
\end{abstract}

Published under license by AIP Publishing. https://doi.org/10.1063/1.5054703

\section{INTRODUCTION}

State of the art PERC (passivated emitter rear contact) solar cells ${ }^{1}$ typically use a backside passivation that is optimized to contain a high density of fixed charges $\left(\mathrm{Q}_{\mathrm{fix}}\right)$ together with a very low interface trap density $\left(D_{i t}\right){ }^{2}$ However, in the PERC concept, a contact through the passivation is required, leading to a significantly increased carrier recombination below the contacts as well as additional processing steps. In contrast, passivating carrier-selective contacts on Si heterojunction solar cells allow for nearly recombination-free interfaces and extraction of either electron or holes and avoid local destruction of the passivation layers. These contacts can be based on thin intrinsic and doped hydrogenated amorphous $\mathrm{Si}$ or on dopant-free dielectric materials. ${ }^{3}$ Examples for the latter include for electron selective contacts $\mathrm{TiO}_{2},{ }^{4}$ tunnel-SiO$/$ $\mathrm{TiO}_{2},{ }^{5,6} \mathrm{LiF}_{\mathrm{x}}{ }^{7}$ or $\mathrm{MgF}_{2}{ }^{8}$ and for hole selective contacts $\mathrm{MoO}_{\mathrm{x}}{ }^{7,9,10}$ or $\mathrm{WO}_{\mathrm{x}}{ }^{10}$ However, temperature stability of these materials remains an issue ${ }^{3,5,10}$ as well as the scalability and costs incurred with thermal evaporation under high vacuum when alternative standard methods such as sputter deposition or atomic layer deposition (ALD) cannot be used.

Recently, we demonstrated that one Al-O monolayer (ML) from a single ALD- $\mathrm{Al}_{2} \mathrm{O}_{3}$ cycle embedded in thin $\mathrm{SiO}_{2}$ can create significant negative $\mathrm{Q}_{\text {fix }}$ and this enables efficient field-effect passivation combined with improved hole tunneling. ${ }^{11}$ The origin of $\mathrm{Q}_{\text {fix }}$ was identified as Al-induced acceptor states at the $\mathrm{SiO}_{2} / \mathrm{Al}_{2} \mathrm{O}_{3}$ interface with an energy level $0.5-0.8 \mathrm{eV}$ below the $\mathrm{Si}$ valence band edge that capture 
electrons from the Si substrate and that act as hopping sites for holes. ${ }^{11,12}$

In this contribution, the correlation between negative $\mathrm{Q}_{\text {fix }}$ and minority carrier lifetimes $\left(\tau_{\text {eff }}\right)$ as a function of the tunnel- $\mathrm{SiO}_{2}$ thickness and the role of $\mathrm{H}_{2}$-passivation are investigated. We show that the interface trap density at the $\mathrm{Si} / \mathrm{SiO}_{2}$ interface depends decisively on the thickness of the tunnel- $\mathrm{SiO}_{2}$ between the wafer and the ALD Al-O MLs. A passivation mechanism is revealed in theory and experiment that involves the electronic deactivation of dangling bonds (DBs) at the $\mathrm{Si} / \mathrm{SiO}_{2}$ interface by interaction with the Al-induced acceptor states.

\section{EXPERIMENTAL DETAILS}

For lifetime measurements of double-side polished $n$-type, $<100>$-oriented $\mathrm{Cz}$-Si wafers $(\sim 5 \Omega \mathrm{cm}, 525 \mu \mathrm{m}$ thick) and for electrical characterization single-side polished $n$-type, $<100>$-oriented $\mathrm{Cz}$-Si wafers $(\sim 2 \Omega \mathrm{cm}, 525 \mu \mathrm{m}$ thick) were used. After RCA-cleaning (Radio Corporation of America) including a final HF-dip, a wedge-shaped tunnel- $\mathrm{SiO}_{2}$ thickness gradient was fabricated by rapid thermal oxidation (RTO; $13 \mathrm{~nm}$ ) and motorized dipping in diluted buffered HF (slantetching) with an etch rate adjusted to fully etch the $\mathrm{SiO}_{2}$ at the lower part of the wafer, followed by immediate rinsing in DI-water and subsequent deposition of 6 plasma-ALD $\mathrm{Al}_{2} \mathrm{O}_{3}$ cycles $(\sim 7.5 \AA)$ and $20 \mathrm{~nm}$ capping $\mathrm{SiO}_{2}$ (PECVD). Reference samples were identically processed except for omitting the trimethylaluminum (TMA) pulses during ALD, so that no Al-O MLs are grown. All samples were rapid thermally annealed (RTA) in pure $\mathrm{Ar}$ at $900^{\circ} \mathrm{C}$ for $30 \mathrm{~s}$ to form the Al-induced acceptor states. ${ }^{11} \mathrm{H}_{2}$-passivation took place in the pure- $\mathrm{H}_{2}$ atmosphere for $1 \mathrm{~h}$ at $400^{\circ} \mathrm{C}$. Aluminum contacts for electrical characterization were thermally evaporated. High-frequency capacitance-voltage $(\mathrm{C}-\mathrm{V})$ and conductance-voltage $(\mathrm{G}-\mathrm{V})$ curves were measured at $300 \mathrm{kHz}$ and interface trap densities were determined via the method proposed by Brews. ${ }^{13}$ The interface state energy distribution over the bandgap was determined by quasi-static $\mathrm{C}-\mathrm{V}$ measurements. ${ }^{14}$ Effective minority carrier lifetimes were measured by microwave detected photoconductance (MDPmap, Freiberg Instruments $\mathrm{GmbH}$ ) using a $976 \mathrm{~nm}$ laser with a power of $20 \mathrm{~mW}$.

\section{RESULTS AND DISCUSSION}

Figure 1(a) shows the relative fixed charged densities $\left(\mathrm{Q}_{\text {fix.rel}}\right.$; derived from the flatband voltage $\left(\mathrm{V}_{\mathrm{FB}}\right)$ shift $^{15}$ of the $\mathrm{Al}-\mathrm{O}$-samples (samples $\mathrm{W}$ ) with respect to $\mathrm{V}_{\mathrm{FB}}$ of the $\mathrm{Al}-\mathrm{O}$-free references (samples $\mathrm{R}$ ), whose positive $\mathrm{Q}_{\mathrm{fix}}$ are in the lower $10^{11} \mathrm{~cm}^{-2}$ range) as a function of tunnel- $\mathrm{SiO}_{2}$ thickness. As demonstrated before, maximum $\left|\mathrm{Q}_{\text {fix }}\right|$ values are observed in the range of $\sim 2 \mathrm{~nm}$ tunnel- $\mathrm{SiO}_{2}{ }^{12}$ Thicker tunnel- $\mathrm{SiO}_{2}$ layers result in very low electron tunneling current densities from the substrate into the Al-induced acceptor states. In contrast to Ref. 12 (where thermal ALD was used for $\mathrm{Al}_{2} \mathrm{O}_{3}$ deposition), a clear minimum tunnel- $\mathrm{SiO}_{2}$ thickness is hardly observed here. Hence, in the case of plasma-ALD for Al-O ML deposition, insufficient formation of
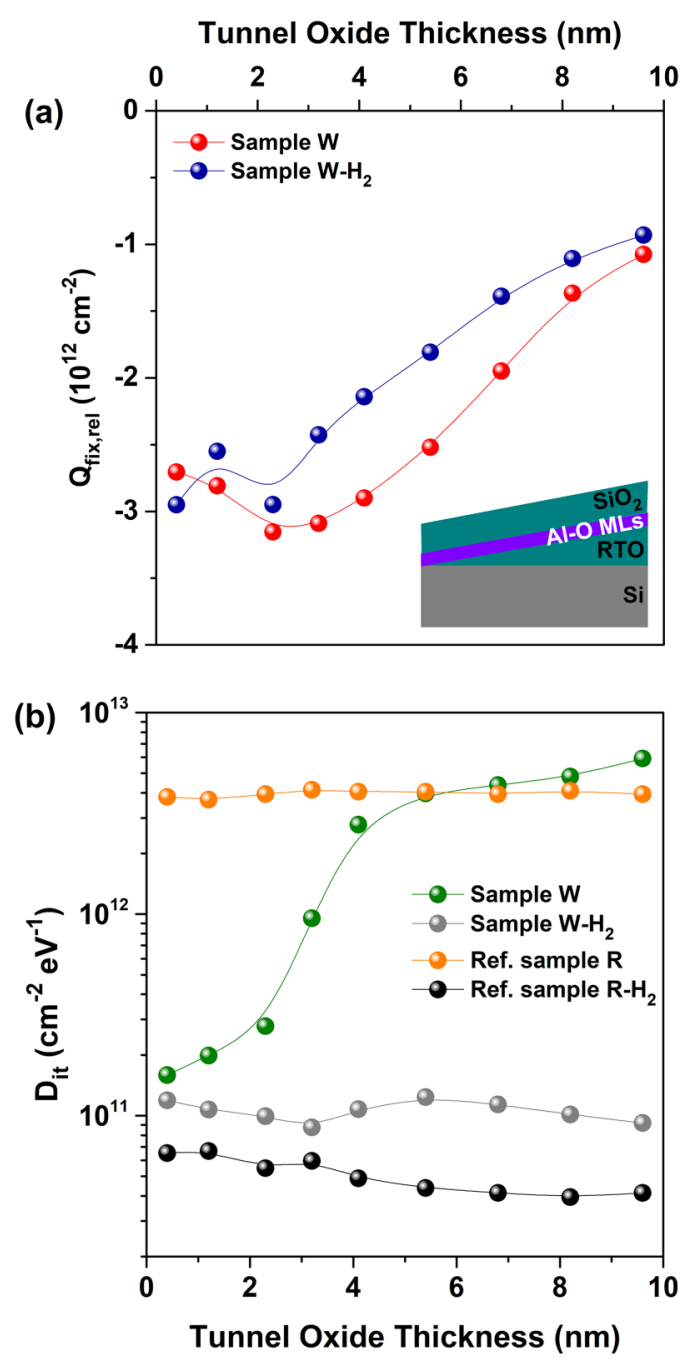

FIG. 1. (a) Relative fixed charge densities $\left(Q_{\mathrm{fix}, \text { rel }}\right)$ and (b) interface trap densities $\left(D_{i t}\right)$ of the samples with slant-etched, wedge-shaped tunnel-SiO${ }_{2}$ and $6 \mathrm{Al}-$ $\mathrm{O} \mathrm{MLs}$ before and after $\mathrm{H}_{2}$-passivation, as a function of tunnel- $\mathrm{SiO}_{2}$ thickness. The inset in (a) depicts a schematic cross section of the layer stack of sample W. All lines (splines) are just a guide to the eye. $\mathrm{H}_{2}$-passivation causes a decrease in $\mathrm{Q}_{\mathrm{fix}}$. For ultra-thin tunnel-SiO $\mathrm{O}_{2}$ thicknesses, $\mathrm{D}_{\text {it }}$ is decreased to the level of $\mathrm{H}_{2}$-passivated samples due to the discharge of DBs into Al-induced acceptor states in $\mathrm{SiO}_{2}$.

acceptor states due to too thin (or fully etched) $\mathrm{SiO}_{2}$ is less expressed due to the oxidation of the exposed $\mathrm{Si}$-surface by the O-plasma.

The effect of $\mathrm{H}_{2}$-passivation appears to be detrimental to the $\mathrm{Q}_{\mathrm{fix}}$ density. Though there is little effect of $\mathrm{H}_{2}$ on $\mathrm{Q}_{\mathrm{fix}}$ for up to $\sim 2.5 \mathrm{~nm}$ tunnel- $-\mathrm{SiO}_{2}$, the reduction is up to $\sim 30 \%$ for thicker oxides (equivalent to a negative $\mathrm{Q}_{\text {fix }}$ loss of up to $7.5 \times 10^{11} \mathrm{~cm}^{-2}$ ). Taking the atomic structure of the Al-induced acceptor state in $\mathrm{SiO}_{2}$ into account (i.e., a fully O-coordinated, 
trivalent $\mathrm{Al}$-atom replacing a $\mathrm{Si}$-atom in the $\mathrm{Si}-\mathrm{O}$ tetrahedrons of $\mathrm{SiO}_{2}$, which creates an O-DB), ${ }^{11}$ it seems possible that the $\mathrm{H}_{2}$-passivation can deactivate some of the acceptor states from which the negative $\mathrm{Q}_{\text {fix }}$ originates. Apparently, a typically used $\mathrm{Si} / \mathrm{SiO}_{2}$ passivation process $\left(400^{\circ} \mathrm{C}, 1 \mathrm{~h}, 100 \% \mathrm{H}_{2}\right)$ is (luckily) far less efficient for passivating the acceptor states than for $\mathrm{P}_{\mathrm{b}}$-type $\mathrm{DB}$-defects at the $\mathrm{Si} / \mathrm{SiO}_{2}$ interface. ${ }^{16}$ In addition to electrons from the $\mathrm{Si}$-substrate, the $\mathrm{P}_{\mathrm{b}}$-type defects also represent a source of electrons to charge the acceptor states, as shown before by electron spin resonance (ESR). ${ }^{12}$ Therefore, it is conceivable that their removal by $\mathrm{H}_{2}$ results in less $\mathrm{Q}_{\text {fix }}$.

The well-known efficiency of $\mathrm{H}_{2}$-passivation in reducing interface traps $\left(D_{i t}\right)$ is shown in Fig. $1(b): D_{i t}$ of the Al-free reference samples is reduced from $\sim 4 \times 10^{12} \mathrm{~cm}^{-2} \mathrm{eV}^{-1}$ (orange data points) to $\sim 5 \times 10^{10} \mathrm{~cm}^{-2} \mathrm{eV}^{-1}$ (black data points). Most surprisingly, the presence of only $6 \mathrm{Al}-\mathrm{O}$ MLs $(\sim 7.5 \AA)$ separated by $\leq 2.5 \mathrm{~nm}$ tunnel- $\mathrm{SiO}_{2}$ from the $\mathrm{Si}$-surface, causes a $\mathrm{D}_{\text {it }}$ drop to the lower $10^{11} \mathrm{~cm}^{-2} \mathrm{eV}^{-1}$ range (green data points, sample $\mathrm{W}$ ), without any $\mathrm{H}_{2}$-passivation. In fact, the additional passivation with $\mathrm{H}_{2}$ (gray data points, sample $\mathrm{W}-\mathrm{H}_{2}$ ) decreases $\mathrm{D}_{\mathrm{it}}$ only marginally in the tunnel- $\mathrm{SiO}_{2}$ thickness range. For tunnel- $\mathrm{SiO}_{2}$ thicknesses of $\geq 4 \mathrm{~nm}, \mathrm{D}_{\text {it }}$ of sample $\mathrm{W}$ approaches the values of the Al-free reference. The extremely steep increase of $D_{i t}$ by one order of magnitude over less than $2 \mathrm{~nm}$ of tunnel- $\mathrm{SiO}_{2}$ in sample $\mathrm{W}$ [green data points in Fig. 1(b)] does not resemble the tunnel- $\mathrm{SiO}_{2}$ thickness function of the $\mathrm{Q}_{\text {fix }}$ density [red data points in Fig. 1(a)] and requires a detailed explanation. Please note that the $D_{\text {it }}$ values reported in Fig. 1(b) refer to a Fermi energy at the $\mathrm{Si} / \mathrm{SiO}_{2}$ interface near the flatband condition, which for the substrate used here corresponds to $\sim 0.88 \mathrm{eV}$ above the Si valence band maximum.

The meanwhile established explanation for chemical passivation of thick $\mathrm{ALD}-\mathrm{Al}_{2} \mathrm{O}_{3}$ films deposited directly on $\mathrm{Si}$ involves the passivation of $\mathrm{DBs}$ by hydrogen ${ }^{17-19}$ and/or oxygen ${ }^{20}$ diffusing from the $\mathrm{Al}_{2} \mathrm{O}_{3}$ to the $\mathrm{Si} / \mathrm{SiO}_{2}$ interface. This is supported by the fact that the typical annealing to activate the surface passivation is often at $400-450{ }^{\circ} \mathrm{C}$ for 15-30 min, ${ }^{21}$ i.e., conditions well suited to $\mathrm{H}$-passivate DBs at the $\mathrm{Si} / \mathrm{SiO}_{2}$ interface. ${ }^{16}$ In contrast, the RTA conditions used here have a temperature far too high $\left(900^{\circ} \mathrm{C}\right)$ and a time far too short $(30 \mathrm{~s})$ for efficient interface defect passivation. ${ }^{16}$ We note that the $\mathrm{H}$-atoms available from just one $\mathrm{ALD}-\mathrm{Al}_{2} \mathrm{O}_{3}$ cycle (even if assuming low $\mathrm{H}$-concentrations of only $\sim 1$ at. $\%)^{18}$ would be sufficient for an almost complete DB passivation. Also, the diffusion lengths of $\mathrm{H}$ - and O-related species from $\mathrm{Al}_{2} \mathrm{O}_{3}$ through the $\mathrm{SiO}_{2}$ are several orders of magnitude longer during the RTA than the tunnel- $\mathrm{SiO}_{2}$ thicknesses used here (for diffusion parameters, see, e.g., Ref. 22). Hence, chemical passivation of the Si-surface cannot be impeded by the critical $\sim 4 \mathrm{~nm}$ tunnel- $\mathrm{SiO}_{2}$ thickness found here, which clearly points toward an electronic explanation.

At the (100) $\mathrm{Si} / \mathrm{SiO}_{2}$ interface, two paramagnetic (singly occupied) and amphoteric defect centers are observed, $\mathrm{P}_{\mathrm{b} 0}$ and $\mathrm{P}_{\mathrm{b} 1}$. The $\mathrm{P}_{\mathrm{b} 1}$ center is a Si point defect involving a strained Si-backbond, ${ }^{23}$ whereas the $\mathrm{P}_{\mathrm{bo}}$ center is configured as $\mathrm{Si}_{3} \equiv \mathrm{Si} \bullet$ (where $\bullet$ symbolizes the unpaired electron). ${ }^{24}$ The $\mathrm{P}_{\mathrm{bo}}$ center exhibits an electrically observable $0 \leftrightarrow 1$ charge transition level (sometimes also denoted $+/ 0$ ) at $0.3 \mathrm{eV}$ above the Si valence band edge. ${ }^{25}$ The electrical activity of $\mathrm{P}_{\mathrm{b} 1}$ as an interface trap is a matter of debate ${ }^{26,27}$ but the reported $0 \leftrightarrow 1$ charge transition level is located ca. $0.45 \mathrm{eV}$ above the $\mathrm{Si}$ valence band edge. ${ }^{26}$

In order to study the interaction of the interface defects with the Al-induced acceptor states in more detail, we plot in Fig. 2 their energy distribution over the bandgap for the samples with $1.2 \mathrm{~nm}$ tunnel- $\mathrm{SiO}_{2}$. For the $\mathrm{Al}$-free reference sample (orange data points), a clear peak at $\mathrm{E}=\mathrm{E}_{\mathrm{V}}(\mathrm{Si})+0.77 \mathrm{eV}$ is observed (dashed line), which corresponds to the $1 \leftrightarrow 2$ charge transition level of the $\mathrm{P}_{\mathrm{bo}}$ center, i.e., the occupation of the singly occupied defect level with a second electron. ${ }^{25}$ This peak is absent for all other samples, indicating that both $\mathrm{H}_{2}$-passivation and $\mathrm{Al}-\mathrm{O}$ MLs suppress the $1 \leftrightarrow 2$ charge transition of the $\mathrm{P}_{\mathrm{bo}}$ center, in accordance with the data shown in Fig. 1(b). In the lower half of the bandgap, where the trap states cannot be probed with the high-frequency conductance method [Fig. 1(b)], the Al-free reference sample shows a high density of $0 \leftrightarrow 1$ charge transitions, which do not form a clear peak due to limitations of the analysis method (too high trap concentration and insufficient charge reversal of the defect states under strong inversion). However, both samples with $\mathrm{Al}-\mathrm{O}$ MLs (green and gray data points) exhibit a distinct peak at $E=E_{V}(\mathrm{Si})+0.28 \mathrm{eV}$ (dotted line) indicative of the $0 \leftrightarrow 1$ charge transition, ${ }^{25}$ i.e., irrespective of $\mathrm{H}_{2}$-passivation, whereas for the $\mathrm{H}_{2}$-passivated reference sample, no peak in that energy range is observed.

The observation that the samples with Al-O MLs only allow for the $0 \leftrightarrow 1$ charge transition means that the defect level can still be occupied with one electron during the $\mathrm{C}-\mathrm{V}$ measurements but not with a second electron, indicating that

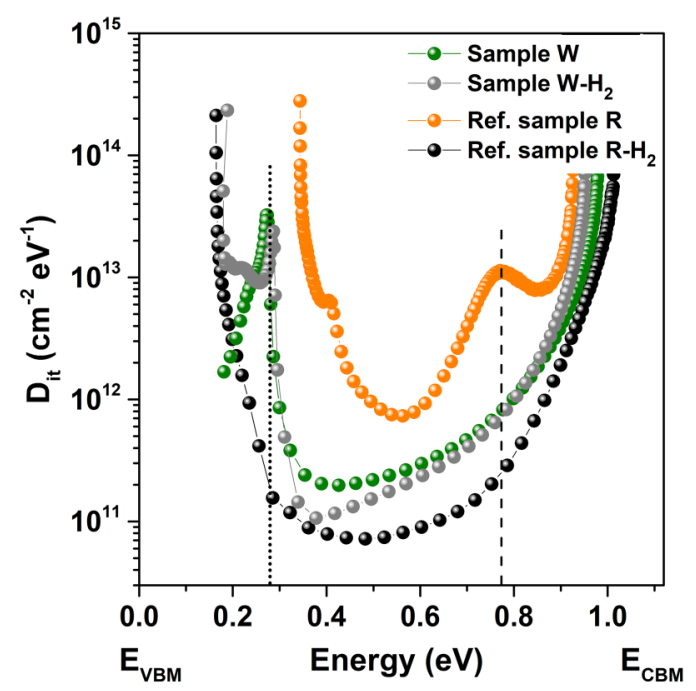

FIG. 2. Energy distribution of the interface defects over the bandgap for the samples with $1.2 \mathrm{~nm}$ tunnel- $\mathrm{SiO}_{2}$. The $0 \leftrightarrow 1$ charge transition level is marked with a dotted line and the $1 \leftrightarrow 2$ charge transition level with a dashed line. 


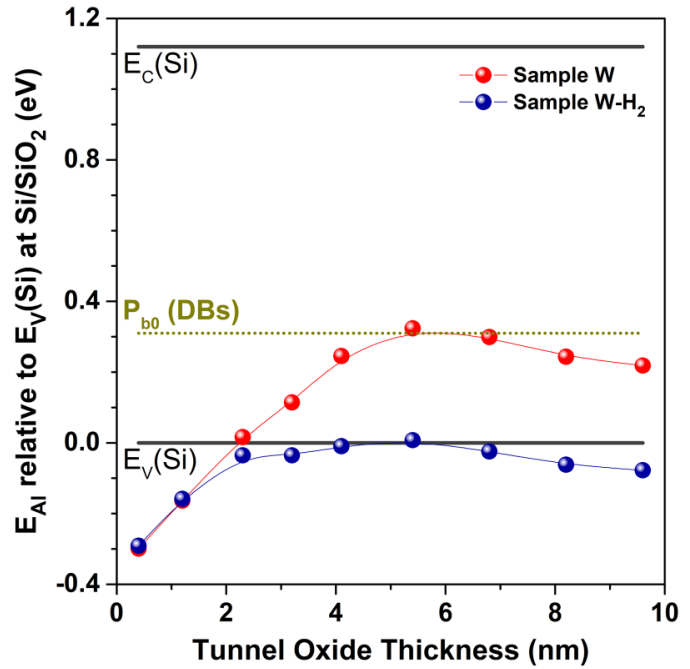

FIG. 3. Energy level of Al-induced acceptor states in $\mathrm{SiO}_{2}\left(E_{\mathrm{Al}}\right)$ as a function of tunnel- $\mathrm{SiO}_{2}$ thickness relative to the valence band edge of $\mathrm{Si}$ at the interface to $\mathrm{SiO}_{2}\left[E_{V}(\mathrm{Si})\right]$, calculated by a one-dimensional Poisson-Solver over the entire MIS structure. The $\mathrm{P}_{\mathrm{b} 0}$ defects originating from $\mathrm{DBs}$ at the $\mathrm{Si} / \mathrm{SiO}_{2}$ interface are located $0.3 \mathrm{eV}$ above $E_{V}(\mathrm{Si})$ as shown in dark yellow.

the defect is in the charge state 0 in its ground state. This strongly supports our explanation that Al-induced acceptor states in a tunneling distance to the $\mathrm{Si} / \mathrm{SiO}_{2}$ interface discharge the $\mathrm{P}_{\mathrm{bo}}$ defect centers.

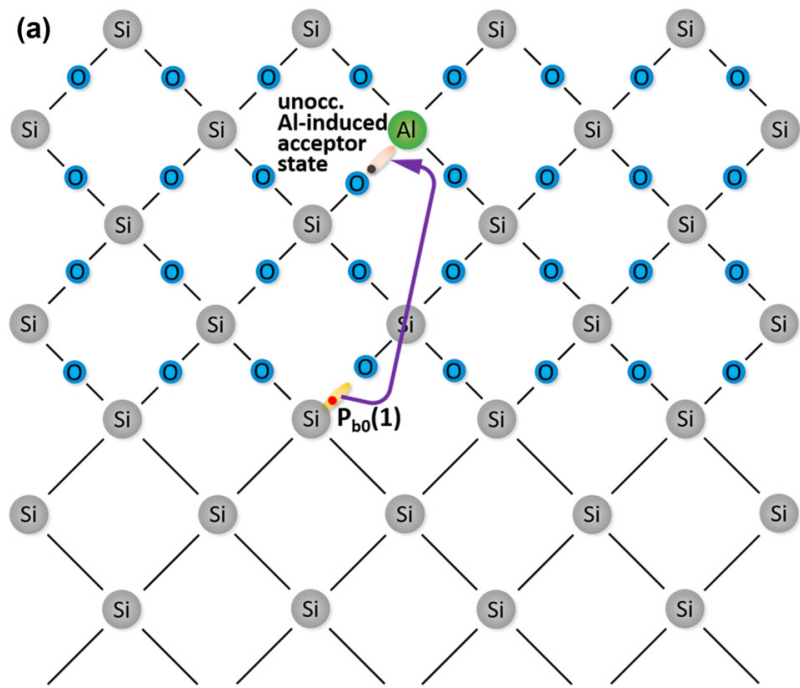

During annealing in $\mathrm{H}_{2}$ gas, molecular hydrogen diffuses toward the $\mathrm{Si} / \mathrm{SiO}_{2}$ interface, dissociates at the $\mathrm{Si} \mathrm{DB}$ and passivates the $\mathrm{P}_{\mathrm{bo}}$ center via an $\mathrm{Si}-\mathrm{H}$ bond. ${ }^{16}$ Thereby, the unpaired electron of the Si-atom is fixed in a bond with $\mathrm{H}$ and no longer an electrically active point defect. Based on the electronegativity values $(\mathrm{EN}[\mathrm{H}]=2.2, \mathrm{EN}[\mathrm{Si}]=1.7), \mathrm{H}$ is anionic against $\mathrm{Si}$ so that the $\mathrm{Si}$-atom has to provide the electron for the polar covalent $\mathrm{Si}-\mathrm{H}$ bond. On first sight, it might appear as a surprise that the $\mathrm{H}_{2}$-passivated $\mathrm{Al}-\mathrm{O}$ sample (gray data points in Fig. 2) also shows the $0 \leftrightarrow 1$ charge transition (in contrast to the $\mathrm{H}_{2}$-passivated reference sample, black data points). However, taking the above discussion and the process sequence into account, this can be explained as well: the Al-induced acceptor states are formed during RTA and immediately start capturing electrons from the $\mathrm{P}_{\mathrm{bo}}$ centers, which discharges them and leaves no electron at the Si DB to bind to $\mathrm{H}$ during the subsequent $\mathrm{H}_{2}$-annealing. Once discharged the $\mathrm{P}_{\mathrm{bo}}$ centers cannot be chemically $\mathrm{H}_{2}$-passivated anymore, but they can be temporarily occupied with an electron during the $\mathrm{C}-\mathrm{V}$ measurement with a transition energy in the lower quarter of the Si-bandgap.

We calculate the energy level of the Al-induced acceptor $E_{\mathrm{Al}}$ relative to the $\mathrm{Si}$ valence band edge $\mathrm{E}_{\mathrm{V}}(\mathrm{Si})$ at the $\mathrm{Si} /$ $\mathrm{SiO}_{2}$ interface using a one-dimensional (1D) Poisson-Solver (coded in MatLab following Nicollian and Brews ${ }^{15}$ ) and the $\mathrm{C}-\mathrm{V}$ data of Fig. 1. We presume for simplicity the ionized acceptor states to be at one depth position in the center of the $6 \mathrm{Al}-\mathrm{O}$ MLs instead of being located at both $\mathrm{SiO}_{2} / \mathrm{Al}-\mathrm{O}$ interfaces $^{12}$ (due to the ultrathin Al-O layer, the discrepancy is considered negligible) and having a relaxation energy of

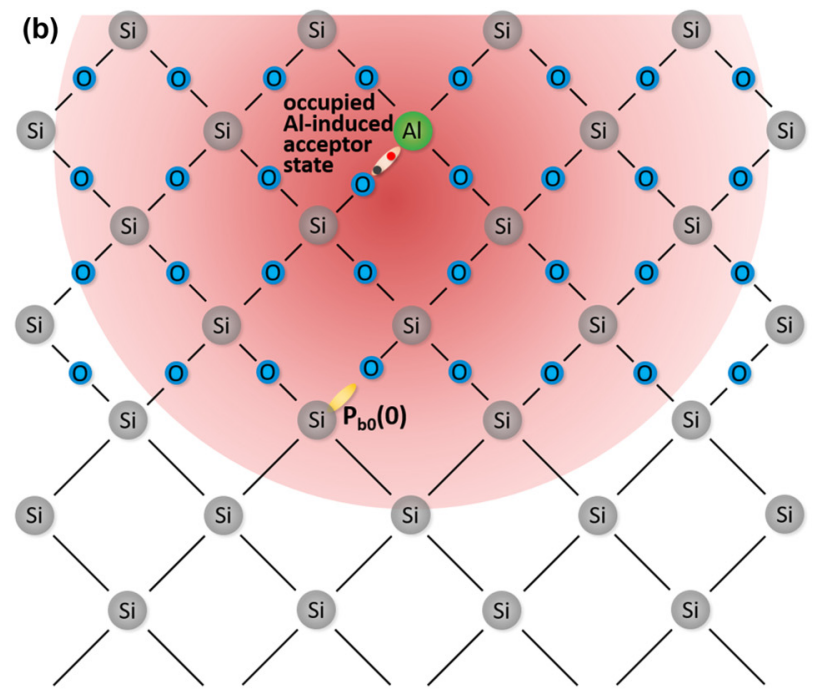

FIG. 4. Schematic illustration of the dangling bond discharge model. (a) In the initial state, the $P_{b 0}$ defect is occupied with one electron (charge state 1), whereas the Al-induced acceptor state at the $\mathrm{Al}-\mathrm{O} / \mathrm{SiO}_{2}$ interface is unoccupied $\left(\mathrm{Al}^{0}\right)$. Tunneling of the electron from the $\mathrm{P}_{\mathrm{b} 0}$ defect into the acceptor state allows for a substantial energy relaxation. (b) After tunneling, the $P_{b 0}$ defect is unoccupied (charge state 0 ) and the acceptor state is occupied ( $\mathrm{Al}^{-}$). The additional electron in the dielectric has an

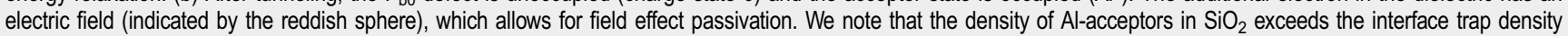
considerably. 
$\mathrm{E}_{\mathrm{Al}} \approx \mathrm{E}_{\mathrm{V}}(\mathrm{Si})-0.6 \mathrm{eV}{ }^{11}$ Half of the $6 \mathrm{ML} \mathrm{Al}-\mathrm{O}$ thickness was added to both the tunnel- $\mathrm{SiO}_{2}$ and the capping- $\mathrm{SiO}_{2}$. Figure 3 shows the $\mathrm{E}_{\mathrm{Al}}$ values as a function of tunnel- $\mathrm{SiO}_{2}$ thickness for the unpassivated and the $\mathrm{H}_{2}$-passivated $\mathrm{W}$-sample. With increasing tunnel- $\mathrm{SiO}_{2}$ thickness, the high field strength of the charged acceptors induces a potential lift of their energy level. The strong drift field for $\leq 2.3 \mathrm{~nm}$ tunnel- $\mathrm{SiO}_{2}$ leads to a nearly equal shift of $\mathrm{E}_{\mathrm{Al}}$ against $\mathrm{E}_{\mathrm{V}}(\mathrm{Si})$ for both samples, which is corroborated by matching $\mathrm{Q}_{\mathrm{fix}}$ values in Fig. 1(a). However, when $E_{\mathrm{Al}}$ raises above $E_{\mathrm{V}}(\mathrm{Si})$, the samples show a very different behavior. For sample $\mathrm{W}-\mathrm{H}_{2}, \mathrm{E}_{\mathrm{Al}}$ remains energetically very close to $\mathrm{E}_{\mathrm{V}}(\mathrm{Si})$ for all tunnel- $\mathrm{SiO}_{2}$ thicknesses $\geq 2.3 \mathrm{~nm}$. In contrast, the unpassivated sample $W$ has a much steeper rise of $E_{\mathrm{Al}}$ over $E_{\mathrm{V}}(\mathrm{Si})$ and reaches a maximum value of $E_{V}(S i)+0.32 \mathrm{eV}$ for a tunnel- $\mathrm{SiO}_{2}$ thickness of $5.4 \mathrm{~nm}$. This energy coincides exactly with the $0 \leftrightarrow 1$ charge transition level of $\mathrm{P}_{\mathrm{bo}}$ defects (indicated by the dark yellow dotted line in Fig. 3). Hence, no energy is gained by electrons tunneling from the $\mathrm{P}_{\mathrm{bo}}$ defects into the Al-induced acceptor states, and consequently, the $\mathrm{D}_{\mathrm{it}}$ values of sample $\mathrm{W}$ and the $\mathrm{Al}-\mathrm{O}$-free reference sample match for tunnel oxides $\geq 5.4 \mathrm{~nm}$ [cf. green and orange data points in Fig. 1(b)].

In other words, when considering the not- $\mathrm{H}_{2}$-passivated sample, the $\mathrm{P}_{\mathrm{bo}}$ defects are efficiently and nearly completely unoccupied (deactivated) due to the large energy difference for electron relaxation into Al-induced acceptor states for tunnel- $\mathrm{SiO}_{2}$ thicknesses of up to $\sim 3 \mathrm{~nm}$. As $\mathrm{E}_{\mathrm{Al}}$ approaches the charge transition level of the $\mathrm{P}_{\mathrm{bo}}$ defects for tunnel oxides thicker than $\sim 3 \mathrm{~nm}$, the relaxation energy decreases and an increasing number of $\mathrm{P}_{\mathrm{bo}}$ defects become reoccupied, which restores their recombination activity. Accordingly, $\mathrm{D}_{\mathrm{it}}$ increases sharply around $3 \mathrm{~nm}$ tunnel- $\mathrm{SiO}_{2}$ thickness [Fig. 1(b)].

We note that these results support the concept of the electrical inactivity of the $\mathrm{P}_{\mathrm{b} 1}$ defect as an interface trap, in accordance with Stesmans and Afanas'ev. ${ }^{27}$

An in-depth discussion of the tunneling properties, accompanying schematic band structures (Fig. 7) as well as a possible explanation for the $\mathrm{E}_{\mathrm{Al}}$ decrease for tunnel oxides thicker than $\sim 5 \mathrm{~nm}$ can be found in the Appendix.

The process of interface defect deactivation described so far implicates that a dangling bond defect electron becomes a fixed charge in the dielectric, i.e., the defect is not only deactivated, its electron is converted from a recombination center into the source of field-effect passivation as depicted schematically in Fig. 4. Hence, for sufficiently thin tunnel- $\mathrm{SiO}_{2}$ thicknesses $(\leq 3 \mathrm{~nm})$, these combined electronic passivation mechanisms should result in excellent $\mathrm{Si}$-surface passivation irrespective of chemical defect passivation by $\mathrm{H}_{2}$.

Figure 5 shows MDP lifetime mappings at an injection level of $\sim 10^{15} \mathrm{~cm}^{-3}$ of n-type Si half-wafers processed exactly in the same way as the electrically characterized samples discussed so far (except for symmetrical front- and back side $\mathrm{SiO}_{2}$-wedge/Al-O MLs $/ \mathrm{SiO}_{2}$-stacks as usual for lifetime samples). Lifetimes of up to $1.4 \mathrm{~ms}$ are measured for sample $\mathrm{W}$ in the range of $2-3.5 \mathrm{~nm}$ tunnel- $\mathrm{SiO}_{2}$, i.e., where $\mathrm{Q}_{\text {fix }}$ is high and $\mathrm{D}_{\mathrm{it}}$ is small. This lifetime corresponds to an upper limit
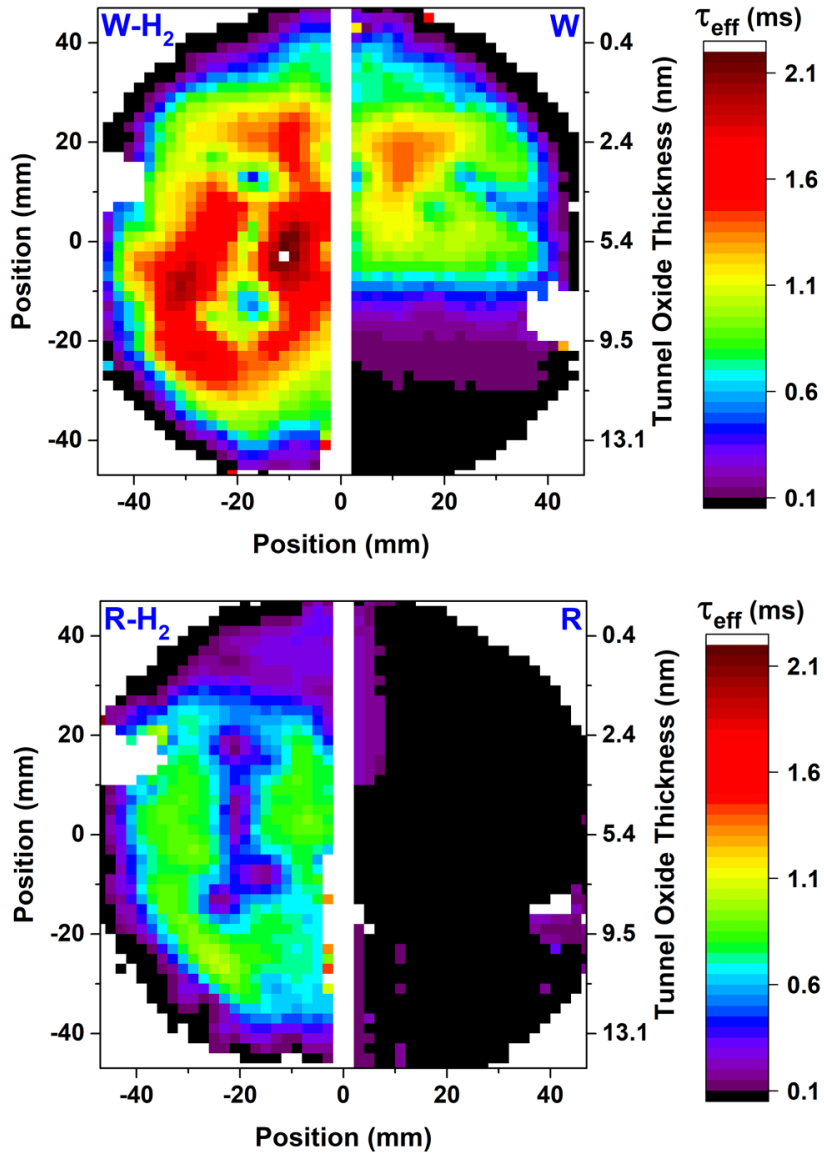

FIG. 5. Minority carrier lifetime $\left(\tau_{\text {eff }}\right)$ mappings at an injection level of $\sim 10^{15} \mathrm{~cm}^{-3}$ of half-wafers with symmetrical $\mathrm{SiO}_{2} / \mathrm{Al}-\mathrm{O}-\mathrm{MLs} / \mathrm{SiO}_{2}$-stacks with slant-etched, wedge-shaped tunnel- $\mathrm{SiO}_{2}$ (W-samples) and Al-O-free references (R-samples), before and after $\mathrm{H}_{2}$-passivation. The tunnel- $\mathrm{SiO}_{2}$ thicknesses are plotted on the right $y$ axes. For the $\mathrm{W}$-samples, similar lifetimes beyond $1 \mathrm{~ms}$ are achieved in the optimum 2-3.5 nm tunnel- $\mathrm{SiO}_{2}$ range, irrespective of $\mathrm{H}_{2}$-passivation, while the $\mathrm{R}-\mathrm{H}_{2}$-sample shows less than half of that lifetime.

for the surface recombination velocity $S_{\text {eff,max }}$ of $\sim 19 \mathrm{~cm} / \mathrm{s}$ (using $S_{\text {eff,max }}=t_{\text {wafer }} / 2 \tau_{\text {eff }}$ with the bulk-lifetime $\tau_{\text {bulk }} \rightarrow \infty$ and $t_{\text {wafer }}$ as the wafer thickness). The loss of high lifetimes toward thicker tunnel- $\mathrm{SiO}_{2}$ is readily explained by a lower $\mathrm{Q}_{\mathrm{fix}}$ density, causing less efficient field-effect passivation and the higher $\mathrm{D}_{\text {it }}$ densities. The reduced lifetimes for tunnel- $\mathrm{SiO}_{2}$ thicknesses below $1 \mathrm{~nm}$ might be attributed to the vicinity of the wafer edge and associated lower surface quality. In addition, Si-surface contaminations from the nearly complete HF-etching of the oxide and subsequent handling can alter the interface properties. The mapping of sample $\mathrm{W}-\mathrm{H}_{2}$ demonstrates that $\mathrm{H}_{2}$-passivation is not capable to significantly further improve the lifetimes in the optimum tunnel- $\mathrm{SiO}_{2}$ thickness range (2-3.5 nm)-as presumed above. A major influence of $\mathrm{H}_{2}$-passivation is mainly observed for tunnel- $\mathrm{SiO}_{2}$ 
thicknesses above $4 \mathrm{~nm}$, where the influence of the Al-induced acceptor states in $D_{\text {it }}$ reduction is marginal. Still, sample $\mathrm{W}-\mathrm{H}_{2}$ has a significantly better surface passivation quality than the reference sample $\mathrm{R}-\mathrm{H}_{2}$, originating from the additional field effect passivation by a $Q_{\text {fix }}$ of yet around $-1 \times 10^{12} \mathrm{~cm}^{-2}$ even for the thickest tunnel- $\mathrm{SiO}_{2}$ used here [cf. Fig. 1(a)]. The unpassivated reference sample $R$ has a featureless average lifetime of about $25 \mu \mathrm{s}$. Hence, the presence of just $6 \mathrm{Al}-\mathrm{O}$ MLs within a suitable tunnel distance from the substrate (sample W) therefore leads to a lifetime increase by a factor of more than 50 .

A detailed discussion of the influence of $\mathrm{H}_{2}$-passivation on the minority carrier lifetimes as a function of minority carrier density (photoconductance measurements) is provided in the supplementary material.

\section{CONCLUSIONS}

In summary, we demonstrated that the midgap interface trap density $\left(D_{i t}\right)$ at the $\mathrm{Si} / \mathrm{SiO}_{2}$ interface can be reduced to a similar level as achieved by conventional $\mathrm{H}_{2}$-passivation due to the presence of just a few Al-O MLs with $\AA$-thicknesses on an ultrathin tunnel- $\mathrm{SiO}_{2}$ of $\leq 2 \mathrm{~nm}$ thickness. The origin of this effect is the discharge of the $\mathrm{P}_{\mathrm{bo}} \mathrm{DB}$-defects into Al-induced acceptor states in $\mathrm{SiO}_{2}$. As a consequence, the discharged DB-defects are no longer deep recombination states so that Shockley-Read-Hall (SRH) recombination is drastically reduced. This constitutes an interface defect deactivation mechanism that is independent from field-effect passivation, i.e., the avoidance of surface recombination at neutral (singly occupied) DBs due to repelling one type of charge carrier by fixed charges in the dielectric. Nevertheless, the transfer of electrons from the $\mathrm{P}_{\mathrm{bo}}$ defects into the Al-induced acceptor states generates a negative $\mathrm{Q}_{\text {fix }}$ that additionally enables field-effect passivation. The combination of this $\mathrm{D}_{\text {it }}$ reduction effect with field effect passivation results therefore in equal effective minority carrier lifetimes on $\mathrm{n}$-type $\mathrm{Si}$ in the optimum tunnel- $\mathrm{SiO}_{2}$ thickness range as chemical defect passivation by annealing in $\mathrm{H}_{2}$. Furthermore, it was revealed that the discharged $\mathrm{P}_{\mathrm{bo}}$ cannot be chemically passivated with $\mathrm{H}_{2}$ due to the absence of an electron at the Si-DB to form the $\mathrm{Si}-\mathrm{H}$ bond. Hence, a final annealing in $\mathrm{H}_{2}$ (or forming gas) becomes a less important process step for the Si-surface passivation since most defects are already deactivated. Importantly, we find little evidence for a direct $\mathrm{H}_{2}$-passivation of the Al-induced acceptor states.

The requirement for tunnel- $\mathrm{SiO}_{2}$ thicknesses of below $3 \mathrm{~nm}$ to benefit from interface defect deactivation by the Al-induced acceptor states are in line with the parameters necessary to maximize $\mathrm{Q}_{\mathrm{fix}}{ }^{12}$ and to enable efficient hole tunneling, ${ }^{11}$ which represents optimum conditions for a passivating hole-selective contact for high-efficiency Si solar cells.

\section{SUPPLEMENTARY MATERIAL}

See supplementary material for photoconductance lifetime measurements of $\mathrm{H}_{2}$-passivated and unpassivated samples.

\section{ACKNOWLEDGMENTS}

D.H. thanks the Alexander von Humboldt Foundation for a Feodor Lynen Fellowship and acknowledges funding by the German Research Foundation (DFG, HI 1779/3-1) and the Australian Centre for Advanced Photovoltaics (ACAP Collaboration Grant). D.H. and D.K. acknowledge funding by the DAAD-Universities Australia joint research cooperation scheme 2016 (No. 57215687). D.K. acknowledges the 2015 Blue Sky research grant of UNSW and the 2018 Theodore-vonKármán-Fellowship of RWTH Aachen University.

\section{APPENDIX: TUNNELING ENERGETICS AND DYNAMICS}

In this appendix, we attempt to explain the energetics and dynamics of tunneling into the Al-induced acceptor states in $\mathrm{SiO}_{2}$ leading to experimental results shown in Figs. 1 and 3.

Direct electron tunneling from the DBs into the $\mathrm{Al}$-induced acceptor states is likely to become a time issue for tunnel- $\mathrm{SiO}_{2}$ thicknesses $\left(d_{\mathrm{t}-\mathrm{Ox}}\right)$ thicker than $\sim 5 \mathrm{~nm}$. A tremendous delay in electron relaxation into the acceptor states results from the macroscopic tunneling time constant $\tau_{\mathrm{T}-\text { macro }}$. The time constant of the quantum-mechanical process $\tau_{\mathrm{T}-\mathrm{QM}}{ }^{28}$ (i.e., the inverse attempt frequency) is in the low fs range for an electron tunneling through a few nanometer of $\mathrm{SiO}_{2}$. However, the macroscopic time constant for exactly one electron being transferred through $\mathrm{SiO}_{2}$ is the product of $\tau_{\mathrm{T}-\mathrm{QM}}$ with the inverse of the electron tunneling probability $\mathrm{T}_{\mathrm{T}}$. While tunneling through ultra-thin barriers proceeds fast enough to extract even hot carriers prior to thermalization, ${ }^{29}$ $\tau_{\mathrm{T}-\text { macro }}=\tau_{\mathrm{T}-\mathrm{QM}} / \mathrm{T}_{\mathrm{T}}$ reaches months or even years for reasonably thick tunnel barriers. For instance, the near-completion of charging acceptor states by ionizing $\mathrm{F}$-vacancies in $\mathrm{AlF}_{3}$ layers on a comparatively thick $(8.2 \mathrm{~nm})$ tunnel- $\mathrm{SiO}_{2}$ was observed after almost 4 years. ${ }^{30}$ The same slow tunneling dynamics might influence the energetic position of Al-induced acceptors in $\mathrm{SiO}_{2}$ relative to the valence band energy of $\mathrm{Si}\left[\mathrm{E}_{\mathrm{V}}(\mathrm{Si})\right]$ at the interface $\mathrm{Si} / \mathrm{SiO}_{2}$.

In Fig. 6, the energy level values of the Al-acceptor states $\left(E_{\mathrm{Al}}\right)$ relative to $\mathrm{E}_{\mathrm{V}}(\mathrm{Si})$ as a function of tunnel-SiO thickness as calculated by a one-dimensional Poisson-Solver are reproduced from Fig. 3. Figure 6 shows that the strong drift field of ca. $2.8 \mathrm{MV} / \mathrm{cm}$ (for $d_{t-\mathrm{Ox}}=0.4 \mathrm{~nm}$ ) to $1.6 \mathrm{MV} / \mathrm{cm}$ (for $d_{t-O x}=2.3 \mathrm{~nm}$ ) is nearly identical for both samples as evident from the nearly equal shift of $E_{\mathrm{Al}}$ against $E_{\mathrm{V}}(\mathrm{Si})$ with $d_{t-\mathrm{Ox}}$, which is confirmed by the nearly identical $\mathrm{Q}_{\text {fix }}$ values in Fig. 1(a). For $d_{t-O x}>2.3 \mathrm{~nm}, E_{\mathrm{Al}}$ raises above $E_{\mathrm{V}}(\mathrm{Si})$ and the $\mathrm{H}_{2}$-passivated and the unpassivated sample show significant differences.

For sample $\mathrm{W}-\mathrm{H}_{2}, \mathrm{E}_{\mathrm{Al}}$ slowly increases with $d_{\mathrm{t}-\mathrm{Ox}}$, reaching a maximum of $\mathrm{E}_{\mathrm{Al}}=\mathrm{E}_{\mathrm{V}}(\mathrm{Si})+0.007 \mathrm{eV}$ for $d_{\mathrm{t}-\mathrm{Ox}}=5.4 \mathrm{~nm}$, before decreasing again to values just below $E_{V}(\mathrm{Si})$. With electrons from $E_{V}(\mathrm{Si})$ relaxing into $\mathrm{Al}$ modulation acceptors, their occupation probability $\mathrm{P}_{\mathrm{Al}}$ is $\mathrm{P}_{\mathrm{Al}}\left(d_{\mathrm{t}-\mathrm{Ox}}=5.4 \mathrm{~nm}\right)=$ $\exp \left\{\left[E_{\mathrm{Al}}-E_{\mathrm{V}}(\mathrm{Si})\right] / k_{\mathrm{B}} \mathrm{T}\right\}=0.43$ at $\mathrm{T}=300 \mathrm{~K}$. The maximum value of $E_{\mathrm{Al}}$ presents the equilibrium point at which $E_{\mathrm{Al}}$ stabilizes against $E_{\mathrm{V}}(\mathrm{Si})$ as indicated by the dashed blue line in Fig. 6. The decrease in $E_{\mathrm{Al}}$ for thicker $d_{t-O x}$ might be due to 


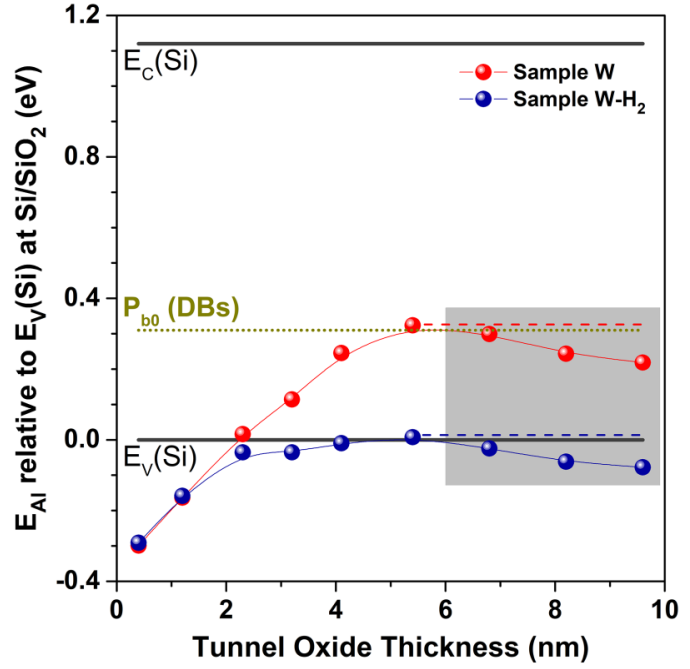

FIG. 6. Energy level of Al-induced acceptor states $E_{\mathrm{Al}}$ relative to the valence band edge of $\mathrm{Si}$ at the $\mathrm{SiO}_{2}$-interface as a function of tunnel- $\mathrm{SiO}_{2}$ thickness $d_{t-0 x}$. The calculated data as derived from a one-dimensional Poisson-Solver are the same as in Fig. 3. The decline of $E_{\mathrm{Al}}$ in the gray highlighted area might be due to increasingly reduced $\mathrm{Al}$ acceptor ionization by the large macroscopic tunneling time constant, which considerably delays the charge relaxation process. As proposed in the text, without this strong time dependence, $E_{\mathrm{Al}}$ should remain constant for $d_{t-0 x}>5 \mathrm{~nm}$. This is indicated by the dashed lines. With increasing $d_{t-0 \mathrm{x}}$, the drift field due to ionized Al-acceptors in $\mathrm{SiO}_{2}$ decreases to keep the energy difference $E_{\mathrm{Al}}\left(\mathrm{SiO}_{2}\right)-E_{V}(\mathrm{Si})$ constant. As a result, the occupation probability $P_{\mathrm{Al}}$ of $\mathrm{Al}$-acceptors decreases with increasing $d_{t-0 \mathrm{x}}$, which leads to a decrease in $\mathrm{Q}_{\mathrm{fix}}$ as shown in Fig. 1 (a).

the substantial time required to reach the charge equilibrium between the Si wafer and the Al-acceptor states. As mentioned, $\tau_{T-\text { macro }}$ increases exponentially with increasing tunnel barrier thickness $d_{t-O x}$ due to its inverse dependence on $\mathrm{T}_{\mathrm{T}}{ }^{30}$ This phenomenon is reflected in $\mathrm{E}_{\mathrm{Al}} \propto \operatorname{Max}\left(\mathrm{E}_{\mathrm{Al}}\right) \times$ $\exp \left(-\tau_{T-\text { macro }} / t\right)$ and shown in Fig. 6 by the gray highlighted area. We note that $t=$ constant since all samples were measured at the same (short) time after fabrication and the quotient in the exponent is in reverse to the usual arrangement due to $\tau_{T-\text { macro }} \propto 1 / \mathrm{T}_{\mathrm{T}}$. Within this concept of the tunneling dynamics of electrons through $\mathrm{SiO}_{2}$, the decrease of $E_{\mathrm{Al}}$ in the gray highlighted area in Fig. 6 would not be a direct feature of the Al-acceptors in $\mathrm{SiO}_{2}$, but an effect related to the time delay in occupying the acceptor states through thick oxide barriers. Under this assumption, the dashed lines in Fig. 6 (blue for sample $\mathrm{W}-\mathrm{H}_{2}$, red for sample $\mathrm{W}$ ) would be the evolution of $E_{\mathrm{Al}}$ with $d_{t-\mathrm{Ox}}$.

Sample W has a much steeper rise of $E_{\mathrm{Al}}$ over $\mathrm{E}_{\mathrm{V}}(\mathrm{Si})$ than sample $\mathrm{W}-\mathrm{H}_{2}$. Its maximum value of $\mathrm{E}_{\mathrm{Al}}=\mathrm{E}_{\mathrm{V}}(\mathrm{Si})+0.324 \mathrm{eV}$ at the same $d_{t-O x}$ value of $5.4 \mathrm{~nm}$ as sample $\mathrm{W}-\mathrm{H}_{2}$ might be due to the same time conditions for electron tunneling. We will elucidate now what impact a $\mathrm{H}_{2}$-passivation has on $\mathrm{E}_{\mathrm{Al}}$ and $\mathrm{P}_{\mathrm{Al}}$ as a function of $d_{t-O x}$, whereby we focus on the $d_{t-O x}$ range not affected by tunneling dynamics. As shown by the

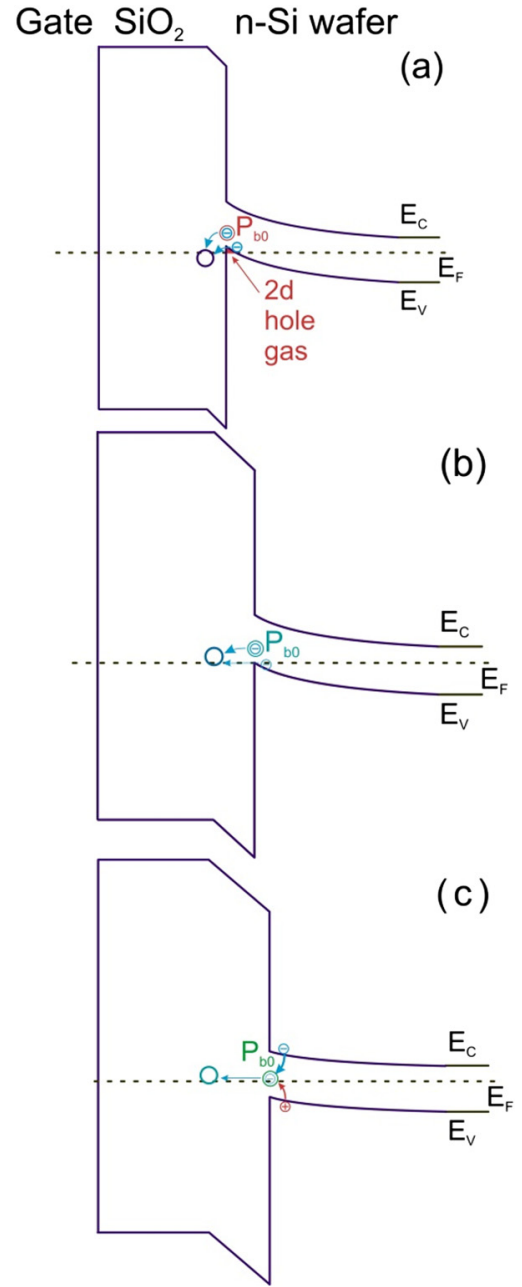

FIG. 7. Simplified band diagrams for the MIS structure of sample $W$ with tunnel- $\mathrm{SiO}_{2}$ thicknesses of $1 \mathrm{~nm}, 3 \mathrm{~nm}$, and $5 \mathrm{~nm}$ based on the $Q_{\mathrm{fix}}$ and $D_{\mathrm{it}}$ data in Fig. 1 and the $E_{\mathrm{Al}}$ values in Fig. 3. (a) $1 \mathrm{~nm}$ tunnel-SiO ${ }_{2}: P_{\mathrm{bo}}$ defects are efficiently discharged by Al-induced acceptor states due to a large energy difference between $E_{\mathrm{Al}}$ and $E_{\mathrm{P}_{\mathrm{b} 0}}$ (relaxation energy). Furthermore, the acceptor states capture electrons from the $\mathrm{Si}$ valence band, which creates a twodimensional hole gas in $\mathrm{Si}$. (b) $3 \mathrm{~nm}$ tunnel-SiO${ }_{2}$ : the $E_{\mathrm{Al}}$ level increases beyond $E_{V}(\mathrm{Si})$ and ionization of Al-acceptor states with electrons from the Si valence band is energetically not favorable and no two-dimensional hole gas exists. In addition, the relaxation energy to the $\mathrm{P}_{\mathrm{b} 0}$ defects is significantly reduced so that some of the defects regain electrical activity as interface trap states $D_{\text {it }}$ [cf. Fig. 1 (b)]. (c) $5 \mathrm{~nm}$ tunnel-SiO ${ }_{2}$ : the relaxation energy for $\mathrm{P}_{\mathrm{b} 0}$ defect electrons vanishes as $E_{\mathrm{Al}}$ approaches $E_{\mathrm{P}_{\mathrm{b} 0}}$. Therefore, the recombination at $\mathrm{P}_{\mathrm{b} 0}$ defects is widely restored and the $D_{\text {it }}$ values of sample $W$ equal those from the Al-acceptor-free reference sample.

reference sample in Fig. 1(b) (orange data points) traps states as represented by $\mathrm{P}_{\mathrm{b} 0}$ centers in the range of $4 \times 10^{12} \mathrm{~cm}^{-2}$ are present at the $\mathrm{Si} / \mathrm{SiO}_{2}$ interface without $\mathrm{H}_{2}$-passivation, which exceeds all $\mathrm{Q}_{\mathrm{fix}}$ values of sample $\mathrm{W}$ measured by $\mathrm{C}-\mathrm{V}$ [cf. Fig. 1(a)]. Such $\mathrm{P}_{\mathrm{b} o}$ centers are occupied with one 
electron and have a characteristic $0 \leftrightarrow 1$ charge transition energy of $\mathrm{E}_{\mathrm{P}_{\mathrm{b} 0}}=\mathrm{E}_{\mathrm{V}}(\mathrm{Si})+0.31 \mathrm{eV}$ at the interface $\mathrm{Si} / \mathrm{SiO}_{2} \cdot{ }^{25}$ These electrons have a preference for relaxing into $\mathrm{Al}$ acceptors over electrons relaxing from $E_{V}(\mathrm{Si})$ since they lose more energy. This process is suppressed mainly by $\mathrm{H}_{2}$-passivation of $\mathrm{P}_{\mathrm{bo}}$ centers and-to a minor extent-by $\mathrm{H}_{2}$-passivation of $\mathrm{O}-\mathrm{DBs}$ at unoccupied $\mathrm{Al}$ acceptors which explains the much lower rise of $E_{\mathrm{Al}}$ over $E_{\mathrm{V}}(\mathrm{Si})$ with increasing $d_{\mathrm{t}-\mathrm{Ox}}$. The occupation probability of $\mathrm{Al}$ acceptors in sample $\mathrm{W}$ is $\mathrm{P}_{\mathrm{Al}}\left(d_{t-\mathrm{Ox}}=5.4 \mathrm{~nm}\right)=\exp \left[\left(\mathrm{E}_{\mathrm{Al}}-\mathrm{E}_{\mathrm{P}_{\mathrm{b} 0}}\right) / k_{\mathrm{B}} \mathrm{T}\right]=0.37$ at $\mathrm{T}=300 \mathrm{~K}$, which is very close to the $\mathrm{P}_{\mathrm{Al}}\left(d_{\mathrm{t}-\mathrm{Ox}}=5.4 \mathrm{~nm}\right)$ value of sample $\mathrm{W}-\mathrm{H}_{2}$. The conditions for Coulomb repulsion between ionized $\mathrm{Al}$-acceptors in $\mathrm{SiO}_{2}$ are virtually identical for both samples, resulting in $\sim 1.4 \%$ of ionized acceptors. ${ }^{12,31}$

Figure 7 shows schematic band structures of sample $\mathrm{W}$ for $d_{t-O x}$ values of 1,3 , and $5 \mathrm{~nm}$ illustrating the discussion above. For ultra-thin tunnel- $\mathrm{SiO}_{2}$ of $1 \mathrm{~nm}$ [Fig. 7(a)], electrons from $\mathrm{P}_{\mathrm{bo}}$ defects relax into the Al-induced acceptor states in addition to electrons tunneling from the Si valence band into acceptor states, generating a two-dimensional hole gas in $\mathrm{Si}$. As a consequence, $\mathrm{P}_{\mathrm{bo}}$ defects cannot provide electrons for recombination with $\mathrm{Si}$ valence band holes, which deactivates their recombination activity. As $d_{t-O x}$ increases to $3 \mathrm{~nm}$ [Fig. 7(b)], the high field strength of charged $\mathrm{Al}$ acceptors induces a potential lift over the tunnel- $\mathrm{SiO}_{2}$ which decreases their occupation probability, resulting in reduced $\mathrm{Si}$ band bending and the loss of hole-degeneracy. $\mathrm{P}_{\mathrm{bo}}$ defects start to participate in surface recombination with the rising Fermi level (increasing occupation probability) due to reduced band bending in Si. Further increase in $d_{t-O x}$ to $5 \mathrm{~nm}$ [Fig. 7(c)] eventually leads to $\mathrm{P}_{\mathrm{bo}}$ defects approaching their nominal occupation probability for undoped $\mathrm{SiO}_{2}$ with the associated recombination activity.

\section{REFERENCES}

${ }^{1}$ H. Huang, J. Lv, Y. Bao, R. Xuan, S. Sun, S. Sneck, S. Li, C. Modanese, H. Savin, A. Wang, and J. Zhao, Sol. Energy Mater. Sol. Cells 161, 14 (2017).

${ }^{2}$ D. K. Simon, P. M. Jordan, T. Mikolajick, and I. Dirnstorfer, ACS Appl. Mater. Interfaces 7, 28215 (2015).

${ }^{3}$ C. Battaglia, A. Cuevas, and S. De Wolf, Energy Environ. Sci. 9, 1552 (2016). ${ }^{4}$ B. Liao, B. Hoex, A. G. Aberle, D. Chi, and C. S. Bhatia, Appl. Phys. Lett. 104, 253903 (2014).
${ }^{5}$ X. Yang, Q. Bi, H. Ali, K. Davis, W. V. Schoenfeld, and K. Weber, Adv. Mater. 28, 5891 (2016).

${ }^{6}$ I. Dirnstorfer, T. Chohan, P. M. Jordan, M. Knaut, D. K. Simon, J. W. Bartha, and T. Mikolajick, IEEE J. Photovolt. 6, 86 (2016).

7J. Bullock, M. Hettick, J. Geissbühler, A. J. Ong, T. Allen, C. M. Sutter-Fella, T. Chen, H. Ota, E. W. Schaler, S. De Wolf, C. Ballif, A. Cuevas, and A. Javey, Nat. Energy 1, 15031 (2016).

${ }^{8}$ Y. Wan, C. Samundsett, J. Bullock, T. Allen, M. Hettick, D. Yan, P. Zheng, X. Zhang, J. Cui, J. McKeon, A. Javey, and A. Cuevas, ACS Appl. Mater. Interfaces 8, 14671 (2016).

${ }^{9}$ C. Battaglia, S. Martín de Nicolás, S. De Wolf, X. Yin, M. Zheng, C. Ballif, and A. Javey, Appl. Phys. Lett. 104, 113902 (2014).

${ }^{10}$ M. Bivour, J. Temmler, H. Steinkemper, and M. Hermle, Sol. Energy Mater. Sol. Cells 142, 34 (2015).

${ }^{11}$ D. König, D. Hiller, S. Gutsch, M. Zacharias, and S. Smith, Sci. Rep. 7, 46703 (2017).

${ }^{12}$ D. Hiller, J. Göttlicher, R. Steininger, T. Huthwelker, J. Julin, F. Munnik, M. Wahl, W. Bock, B. Schoenaers, A. Stesmans, and D. König, ACS Appl. Mater. Interfaces 10, 30495 (2018).

13J. R. Brews, Solid State Electron. 26, 711 (1983).

${ }^{14}$ M. Kuhn, Solid State Electron. 13, 873 (1970).

${ }^{15}$ E. H. Nicollian and J. R. Brews, MOS Physics and Technology (Wiley \& Sons, New York, 1982).

${ }^{16}$ A. Stesmans, J. Appl. Phys. 88, 489 (2000).

${ }^{17}$ M. Schnabel, B. W. H. van de Loo, W. Nemeth, B. Macco, P. Stradins, W. M. M. Kessels, and D. L. Young, Appl. Phys. Lett. 112, 203901 (2018).

${ }^{18}$ G. Dingemans, F. Einsele, W. Beyer, M. C. M. van de Sanden, and W. M. M. Kessels, J. Appl. Phys. 111, 093713 (2012).

${ }^{19}$ A. Richter, J. Benick, M. Hermle, and S. W. Glunz, Appl. Phys. Lett. 104, 061606 (2014).

${ }^{\mathbf{2 0}}$ R. Chaukulkar, W. Nemeth, A. Dameron, P. Stradins, and S. Agarwal, in IEEE Photovoltaic Specialist Conference (IEEE, 2014).

${ }^{21}$ B. Hoex, J. J. H. Gielis, M. C. M. van de Sanden, and W. M. M. Kessels, J. Appl. Phys. 104, 113703 (2008).

${ }^{22} \mathrm{~S}$. W. Jones, Diffusion in Silicon (IC Knowledge LCC, Georgetown, MA, 2008), pp. 34-35.

${ }^{\mathbf{2 3}}$ A. Stesmans, B. Nouwen, and V. V. Afanas'ev, Phys. Rev. B 58, 15801 (1998).

${ }^{\mathbf{2 4}}$ C. R. Helms and E. H. Poindexter, Rep. Prog. Phys. 57, 791 (1994).

${ }^{25}$ E. H. Poindexter, G. J. Gerardi, M.-E. Rueckel, P. J. Caplan, N. M. Johnson, and D. K. Biegelsen, J. Appl. Phys. 56, 2844 (1984).

${ }^{26}$ G. J. Gerardi, E. H. Poindexter, P. J. Caplan, and N. M. Johnson, Appl. Phys. Lett. 49, 348 (1986).

${ }^{27}$ A. Stesmans and V. V. Afanas'ev, J. Phys. Condens. Matter 10, L19 (1998).

${ }^{28}$ C. Bracher, M. Kleber, and M. Riza, Phys. Rev. B 60, 1864 (1999).

${ }^{29}$ D. König, D. Hiller, M. Zacharias, S. Michard, and C. Flynn, Progr. Photovolt. 22, 1070 (2014).

${ }^{30}$ D. König, M. Rennau, and M. Henker, Solid State Electron. 51, 650 (2007).

${ }^{31}$ D. König, D. Hiller, and S. Smith, Phys. Rev. Appl. 10, 054034 (2018). 